\title{
МЕЖДУНАРОДНО-ПРАВОВЫЕ ОСНОВЫ ПРОТИВОДЕЙСТВИЯ ТЕРРОРИСТИЧЕСКОЙ ДЕЯТЕЛЬНОСТИ
}

\section{INTERNATIONAL LEGAL FRAMEWORK FOR COUNTERING TERRORIST ACTIVITIES \\ P. Chuvakhin}

Summary: The article is devoted to the study of the legal basis of international cooperation of states in the prevention of terrorist acts and the need to improve legal norms and the coordination of this issue by international organizations. In modern realities, when such a phenomenon as terrorism has become the main threat to human security, states become vulnerable and incapable of protecting their citizens without competent international cooperation and a well-constructed action plan. The vigorous activity of terrorist groups and the high level of their equipment entails great human casualties, destruction of spiritual and cultural values, as well as an increase in tension among social groups of the population, and, as a consequence, an increase in intrastate clashes between various strata of society. At present, terrorism, which is international in nature and terrifying in its scale and level of brutality, is a challenge to all international principles and values. To preserve and maintain peace and order, states and international organizations make colossal efforts to prevent terrorist acts, but, based on practice, they are not always justified.

Keywords: terrorism, principle aut dedere aut judicare, principle of nationality, principle of jurisdiction by the nature of the crime, international terrorist act.
$\Pi$ ричины террористической активности различны, характеризуются множеством аспектов - от политических до религиозных, но стоит отметить, что на протяжении всего развития человечества терроризм характеризовался не как акт насилия ради самого насилия, а как грамотно спланированная деятельность, осуществляемая ради достижения четко определенных целей, среди которых выделяются корыстные интересы членов таких организаций, иных частных лиц, которые финансируют террористическую деятельность, желание дестабилизировать экономическую, политическую ситуацию, вызвать напряжение и последующие столкновения среди социальных групп.

Ввиду этого следует отметить, что для полного понимания самой сущности терроризма, условий, которые его порождают, и всестороннего регулирования вопроса обеспечения противодействия террористической деятельности просто необходимо осмысление понятия «терроризм» и его основных компонентов.
Чувахин Петр Игоревич

преподаватель, Финансовый университет при Правительстве РФ; старший преподаватель, Российский государственный университет правосудия, г. Москва chuvakhin.petr@yandex.ru

Аннотация: Статья посвящена изучению правовой основы международного сотрудничества государств по предупреждению террористических актов и необходимости совершенствования правовых норм и координации этого вопроса международными организациями. В современных реалиях, когда главной угрозой безопасности для человечества стало такое явление, как терроризм, государства становятся уязвимыми и неспособными без грамотного международного сотрудничества и четко выстроенного плана действий защитить своих граждан. Активная деятельность террористических групп и высокий уровень их оснащенности влечет за собой большие человеческие жертвы, разрушение духовных и культурных ценностей, а также увеличение напряжения среди социальных групп населения, и, как следствие этого, рост внутригосударственных столкновений между различными слоями общества. В настоящее время терроризм, носящий интернациональный характер и ужасающий своей масштабностью и уровнем жестокости, является вызовом для всех международных принципов и ценностей. Для сохранения и соблюдения мира и порядка государствами и международными организациями прилагаются колоссальные усилия по предупреждению террористических актов, но, исходя из практики, они не всегда оправдываются.

Ключевые слова: терроризм, принцип aut dedere aut judicare, принцип национальности, принцип юрисдикции по характеру преступления, международный террористически акт.

Для определения сущности терроризма представляется необходимым раскрыть данное понятие в историческом контексте. Первой известной мировому сообществу в истории террористической группой стала секта сикариев, которая существовала в Палестине в 70-х годах нашей эры. Основоположником самой теории «терроризма» принято считать Хасан аль-Саббаха, который был создателем тайного общества, широко известного на Востоке - сообщества ассасинов. Данные группы занимались террористической деятельностью не совсем в принятом в настоящее время контексте; члены таких групп традиционно выполняли работу наемных убийц и вымогателей для тех, кто готов был заплатить. С массовым политическим террором и террористическими актами мир столкнулся спустя столетия - сильным толчком к этому стала Великая Французская революция, которая породила насильственные расправы со всеми противниками буржуазии и массовые убийства пленных. Здесь содержание дефиниции расширяется, приобретает все новые черты и становится предпосылкой к созданию множества террористических организаций, деятель- 
ность которых сосредотачивалась в разных странах, в том числе и в Европе.

С конца девятнадцатого века, термином «терроризм» стали обозначать деятельность революционно настроенных масс, участников национально-освободительских движений и анархистов, что становится уже гораздо ближе к его традиционному, современному пониманию. Особым примером является серия покушений на Александра II, действия партии русских революционеров «народная воля», совершивших не мало терактов, и в последующем - политика большевиков по устранению врагов идеологии советского строя.

Стоит отметить, что с терроризмом в России тесно связано понятие «красный террор». Имеются различные подходы к его определению, но большинство ученых склоняется к тому, что данный термин представляет собой самостоятельное явление, которое создавалось сознательно революционными массами для сохранения идеологии и дальнейшего использования против целых слоев населения.

Здесь следует провести параллель между двумя терминами: «терроризм» и «террор» и выделить ключевые отличия. По сути, террор является способом, средством устрашения и закрепления власти за конкретным лицом, партией, слоем общества на политической арене, то есть субъектом является государство в лице управляющих органов или институтов, которое осуществляет целенаправленную политику террора, характеризующуюся непрерывностью и массовостью процесса. Терроризм же представляет собой совершение разовых или массовых актов против жизни людей с расчетом на дальнейшее манипулирование поведением международных организаций властных структур или всего международного сообщества. К тому же, совершение террористического акта является преступным деянием, за которое предусматривается уголовная ответственность и национальным, и международным правом.

Перейдем к современной трактовке изучаемого термина. Все существующие определения понятия вытекают из «terror», означающего на латинском «ужас, первородный страх». Обратимся к словарю: Ожегов раскрывает данное понятие как процесс совершения насильственных действий по отношению к противникам, сопровождаемых желанием уничтожить, искоренить. Различные международные и отечественные ученые также раскрывают терроризм неразрывно от дефиниции «насилие» и сопутствующих угроз его осуществления в политических целях.

В связи с этим, представляется необходимым создание определения этого понятия, которое было бы принято мировым сообществом, и первую попытку создать его приняла Лига Наций, утвердившая Конвенцию о предупреждении терроризма 1937 года. В данном документе терроризм закреплялся как «те уголовные деяния, направленные против государства и нацеленные на создание состояния террора в сознании людей, групп, общественности» [1]. Эту попытку сложно назвать удачной, ведь в дальнейшем она так и не вступила в силу - была ратифицирована лишь одним государством из двадцати четырех подписавших. При этом, первое раскрытие исследуемого понятия в международном акте действительно стало началом для формирования и законодательного закрепления определения терроризма рядом стран в своих нормативных правовых актах.

Статьей 205 Уголовного кодекса Российской Федерации закрепляется определение тех общественно-опасных действий, которые трактуются как террористическая деятельность и субъект которых будет привлечен к уголовной ответственности. Такими деяниями будут являться совершение взрыва, поджога или иных, конкретно-определенных действий или же угроза их совершения, при осуществлении которых предусматривается устрашение людей или какая-либо опасность для их жизни, здоровья, а также причинение имущественного ущерба в значительном размере. Помимо этого, подчеркивается, что такие действия должны быть совершены в целях дестабилизации деятельности международных организаций или органов государственной власти, а также в целях влияния на принятие ими решений [2]. То есть, такое преступление носит политический контекст.

Таким образом, подходов к определению понятия «терроризм» довольно много, но представляется необходимым выделить собственное. Терроризм - это деятельность физических лиц и террористических организаций, которая направлена на достижение политических целей путем принуждения к принятию определенных решений и связана с угрозой совершения или с совершением общественно опасных деяний, посягающих на жизнь и здоровье, а также законные права и интересы субъектов.

Классифицировать терроризм можно по различным основаниям: 1) по субъекту - организованный или системный терроризм и неорганизованный (стихийный); 2) негосударственный, государственный и так называемый институционализированный (тот, что спонсируется государством); 3) исходя из характера терроризма - социальный, государственный (политический), этнический и религиозный; 4) внутригосударственный и международный.

В современном мире, терроризм как явление становится все шире, охватывает целые регионы и государства, террористические организации вербуют новых участников, которые распространяют собственную иде- 
ологию среди социальных слоев и жертвуют собой для достижения целей преступников, в связи с чем говорить о терроризме только как о внутригосударственном преступлении - невозможно. Терроризм как преступление (содержащее в себе три главных элемента: преступное лицо, непосредственные жертвы и сам объект эмоционального воздействия) подлежит вынесению за границы «простых» преступных деяний, предусмотренных государствами. Террористическая деятельность все приобретает международный характер, и именно поэтому необходимо определение международного терроризма как главной угрозы для безопасности государств в XXI веке.

Необходимо отметить, что само понятие «международный терроризм» впервые встречается в зарубежной и отечественной литературе в 70-80-е годы прошлого столетия. Примером может служить Трактат американских профессоров В. Нанди и М. Басссиони, в котором приводится примерное определение международного терроризма как международного преступления с рядом признаков: угрожающее спокойствию и безопасности людей, наносящее ущерб имуществу и достоинству, а также оскорбляющее совесть и духовные ценности человечества. При этом, определения такого термина как такового помимо как сформированного различными учеными в доктринальных источниках не предусмотрено до сих пор ни в одном из нормативных правовых актов.

На практике, государствами через призму структурных органов Организации Объединенных Наций (далее - ООН) выделяются следующие основания определения деяния в качестве международного терроризма. Таким образом, международный террористический акт, чтобы являться таковым, должен:

1. Серьезно подрывать основные права и свободы человека;

2. Угрожать международной безопасности и соблюдению мирового порядка;

3. Тормозить или разрушать естественные политические и государственные процессы.

Следует отметить, что единое определение изучаемой дефиниции смогло бы более точно проследить отличия насилия политического от иного, не связанного с такими мотивами, а также обеспечить более унифицированное реагирование на различные виды международного терроризма. Помимо этого, такое решение поможет четко ограничить круг мер, которые могут приниматься государствами для противодействия терроризму в соответствии с Резолюциями Совета Безопасности, и не позволит применять чрезмерные или непредсказуемые средства.

Современный международный терроризм слишком многогранен, его можно охарактеризовать двумя существенными, отличительными чертами: 1) в последнее время увеличивается количество самостоятельных международных террористических организаций, действующих независимо от стран и обладающих высокотехнологичными ресурсами, которые позволяют им держать под контролем отдельные территории, инициировать международные военные конфликты и кооперироваться с иными преступными организациями; 2) в современных реалиях все труднее установить причастность правительств разных стран к поддержке международных террористических организаций.

Ввиду многогранности исследуемого явления, его классификация также является довольно обширной. Видами международного терроризма являются:

1. По субъекту: террористическая деятельность, управляемая государством, отдельными лицами или группировками;

2. По целям формирования:

- Политический или идеологический, в основе которого желание достижения определенных изменений путем принуждения правительственных органов государств;

- Националистический;

- Религиозный - связан с желанием уничтожить неверных и установить собственную религию;

- Криминальный - цель - создание более выгодных условий для наркотрафика и контрабанды через рынки государств;

- Экологический - во главе - желание недопустить строительство различных объектов или убийства животных насильственным методом.

Как уже подчеркивалось, единого определенного понятия международного терроризма не существует, хотя и работа по разработке такой дефиниции ведется, и принимаются различные конвенции и пакты, преследующие основной целью борьбу с ежегодно расширяющейся в масштабе противоправной деятельностью террористических организаций.

Подводя итог вышесказанному, следует отметить, что международный терроризм можно обозначить как осуществление террористической деятельности на территории нескольких государств определенными группировками и физическими лицами, суть которой заключается в совершении или угрозе совершения таких деяний, которые посягают на здоровье, жизнь, а также законные права и интересы человечества, при этом она направлена на достижение политических целей, например на принуждение субъектов к осуществлению тех действий, в которых заинтересованы преступники.

В современных реалиях все более актуальным становится вопрос борьбы с таким явлением, как терро- 
ризм, особенно международный, который выходит за рамки одной территории и посягает на установленные границы государств и их власть. Главной особенностью терроризма является приобретение им характера глобального, широкомасштабного явления, охватывающего ни одно государство. Современный терроризм обладает большими возможностями для коммуникации различных террористических организаций, разнообразными источниками финансирования и достаточным оборудованием для реализации собственных целей, чем представляет глобальную угрозу для всего человечества. Именно поэтому просто необходимо, чтобы государства посредством различных правовых форм сотрудничества имели возможность противостоять террористическим организациям и бороться с терроризмом более эффективно на международной арене.

Существует ряд направлений, в отношении которых государства на международной арене сотрудничают и принимают определенную нормативную базу в виде конвенций, двусторонних и многосторонних соглашений. Данные НПА регулируют вопросы осуществления направлений сотрудничества государств посредством правовых форм взаимодействия государств, о которых будет рассказано позже.

В последнее десятилетие XX века и в начале XXI, после произошедшего 11 сентября 2001 года в США, которые унесли множество человеческих жизней, в мире достаточно остро встал вопрос о необходимости нахождения такого решения, которое могло бы способствовать предотвращению террористических актов и эффективной борьбе с террористическими организациями. Именно в этот период наиболее активно стали проводиться определенные мероприятия, например, саммиты и встречи глав государств, на которых первым пунктом повестки являлся вопрос о выявлении ключевых направлений, по которым стоит действовать государствам в рамках различных международных организаций.

На одной из таких конференций, организованных Организацией Объединенных Наций, в 1993 году в Вене была принята Декларация, которая определяла статус террористических актов и методик террористов в формах - они признаются такой деятельностью, которая прямо нарушает права и свободы людей, которые определены в связи с Пактами о политических, гражданских, экономических, социальных и культурных правах и Декларацией о правах человека; помимо этого, такие действия зачастую нарушают территориальную целостность государства или содружества государств, а также покушается на их безопасность и создает проблему для осуществляющих свои полномочия в государстве властных структур (правительств, министерств, служб).

Результатом устанавливающей вышеуказанные по- ложения Декларации стало инициирование 49-сессии Генеральной Ассамблеи ООН. На данной сессии был принят крупнейший акт по борьбе с терроризмом - Декларация о мерах по ликвидации международного терроризма. Данный документ предусматривает одно из направлений сотрудничества государств - тесную координацию и коммуникацию между странами на международной арене в целях борьбы с противоправными деяниями, то есть террористическими преступлениями.

Особенное внимание уделяется вопросу о борьбе с незаконной торговлей оружием, контрабандой ядерной продукции и иного материала, с ней связанного. Для того, чтобы этот механизм работал, правовыми положениями предусматривается необходимость всестороннего анализа и дополнения, если это необходимо, нормативной базы в сфере ликвидации и предупреждении террористических актах. Данный механизм мог бы обеспечить комплексное регулирование данного вопроса. Но следует отметить, что наиболее эффективным сотрудничеством в данном случае представляется сотрудничество государств в рамках региональных организаций, которые бы объединяли небольшое количество государств (например, ЕАЭС), либо же двустороннее сотрудничество. Данный тезис объясняется отсутствием единообразного правового регулирования ввиду отношения стран к разным правовым системам. Примером является Россия и, например, США. Но к созданию единой системы регулирования борьбы с терроризмом, а не только общих принципов и отраслевых норм, следует стремиться, особенно в современных реалиях.

Следующим направлением является улучшение квалификации специалистов и работников специализированных внутренних органов, что в будущем обеспечит более эффективную борьбу с терроризмом, особенно в вопросе химических, радиоактивных и взрывчатых веществ. В настоящее время большую опасность для мировой безопасности представляют именно подобные террористические атаки, потому как мир помнит множество случаев уничтожения целых районов посредством использования такой разновидности оружия. Проблемой также является тот факт, что очень трудно отследить, откуда террористические организации получают подобные вещи. Данный тезис впервые был озвучен на совещании по противодействию терроризму представителями «Большой восьмерки» в Париже. Помимо этого, там же был согласован список мер для государств по борьбе с терроризмом.

Следует ответить, что ввиду проблематики, обозначенной выше, государства призвали правительства стран особое внимание уделить разработке эффективных методов отслеживания и обнаружения взрывчатых веществ, а также системы взлома и отслеживания устройств по кодированию информации, которой обме- 
ниваются преступники между собой и с организациями, которые их курируют и финансируют (такими могут быть даже неправительственные организации, чья деятельность связана с социальной и культурной сферой жизнедеятельности; такие чаще всего используют для прикрытия незаконного оборота наркотических средств и координирования террористической деятельности) [3].

Отдельными направлениями также выделяются разработка мер по эффективному контролю торговли, производства, экспортирования и импортирования оружия, а также совершенствование национальной правовой базы, особенно в части допуска специальных служб к персональным данным граждан, улучшения контроля на границах таможенными службами и ужесточения ответственности за террористические акты. Следует отметить, что принципиально важное значение имеет вопрос финансирования терроризма правительствами государств и международными преступными организациями, и то, каким образом мировому сообществу следует бороться с подобными незаконными действиями. В связи с этим была принята Резолюция 1373 (2001) Совета Безопасности ООН, ключевым положением которой являлось обязательство участников ввести уголовную ответственность за финансирование терроризма и присоединиться к международным нормативно-правовым актам по противодействию терроризму.

Улучшение взаимодействия и координации деятельности государств по использованию специализированных баз данных, содержащих данные о террористических организациях, а также их членах, и непосредственной выдаче таких лиц является одним из основных направлений международного сотрудничества стран по вопросу предупреждения терроризма и реализуется посредством различных двусторонних и многосторонних соглашений.

Для того, чтобы работа государств в данных направлениях была эффективной, необходимо соблюдение международных принципов, которые создают так называемую основу для грамотного правового регулирования борьбы с терроризмом посредством взаимодействия государств и тех правовых форм сотрудничества, которые они принимают международными актами.

Кроме основных принципов, которые характерны для регламентации любых правовых отношений в национальных правовых системах (речь идет о принципах законности, справедливости, соблюдения прав человека, установления ответственности за совершенные преступления, презумпции невиновности, запрета пыток и другие), действенное сотрудничество государств и эффективное правовое регулирование на международной арене основывается на специализированных принципах [4].
Принципами международного сотрудничества являются:

- Преимущественная сила обязательств членов ООН над обязательствами по другим соглашениям - когда обязательства государств-членов по другим международным соглашениям противоречат обязательствам по Уставу $\mathrm{OOH}$, преимущественной силой обладают обязательства ООН [5];

- Comitas gentium - принцип международной вежливости - способствует поддержанию нормальных взаимоотношений между государствами при сотрудничестве;

- Принцип aut dedere aut judicare (либо выдай, либо суди) - данный принцип позволяет предупредить возможность сокрытия террористов в безопасном убежище, которое ему может предоставить другая страна. На государство возлагается обязательство по привлечению к ответственности преступника внутри страны, на которой он находится, или же выдаче другому государству. Описанный принцип является обязательным и содержится в Резолюции 1373 Совбеза ООН. Существуют также четыре правила по определению юрисдикции принципы территориальности, юрисдикция по принципу «либо выдай, либо суди» и по характеру совершенного преступления, принцип национальности;

- Территориальный принцип - государства могут установить свою юрисдикцию в отношении преступлений, совершенных в пределах данной территории;

- Принцип национальности - данный принцип тесно связан с имеющимся гражданством преступника или же местом его постоянно проживания, а также с гражданством лица, которое потенциально является потерпевшим (активная и пассивная персональная юрисдикция);

- Принцип юрисдикции по характеру преступления - если целью преступления является понуждение государства к каким-либо действиям или оно совершено против посольства или представительства;

- Непринятие политических мотивов - акты терроризма не рассматриваются как политические преступления и не могут быть каким-либо образом оправданы на международной арене, а также государства на основании ссылки на политические мотивы не могут отклонять просьбу о выдаче лица;

- Верховенство права - обеспечение справедливости и демократии для действенности механизма сотрудничества стран на международной арене необходимо;

- Принцип двойного вменения - деяние, которое совершенно террористом, должно являться преступлением в законодательстве двух стран для 
того, чтобы одно государство выдало лицо другому государству по их запросу для привлечения к ответственности;

- Принцип ne bis in idem - запрет на множественность преследования за одно совершенное противоправное деяние, res judicata;

- Поощрение обмена информацией и контактами (на основе принципа взаимности).

Применение вышеуказанных принципов для определения и последующей реализации направлений сотрудничества государств в сфере противодействия терроризму представляется необходимым условием для достижения целей подобного взаимодействия, а именно предупреждения террористических актов и объединения усилий для всесторонней борьбы с организациями, которые инициируют такие акты.

Государства имеют различные правовые системы, соответственно и правовая ответственность за террористическую деятельность в странах разная, но именно принципы и направления, которые определяются в рамках работы Совета Безопасности и всей Организации Объединенных Наций, являются основными началами, которые регламентируют правила международного сотрудничества государств и его содержание, что позволяет странам прийти к определенному консенсусу и эффективно взаимодействовать в вопросе борьбы с главной угрозой безопасности, активно двигаясь к созданию универсального правового регулирования данной проблематики.

Одним из центральных документов в механизме сотрудничества государств по предупреждению терроризма является Глобальная контртеррористическая стратегия, которая была принята Советом Безопасности ООН 8 сентября 2006 года и предусматривала цели международной политики в сфере уголовного права, а также ряд мер, направленных на ограничение или полное устранение причин и условий, которые способствуют распространению террористической деятельности по всему миру. Данный документ также содержал положения о неотвратимости правосудия для тех лиц, которые являлись организаторами террористических актов. В данное направление стратегии включались ключевые вопросы экстрадиции, определения юрисдикции государства по совершенному акту, а также принципы осуществления правосудия над преступниками.

Посредством принятия данной Стратегии, всеми странами, имеющими членство в ООН, был достигнут консенсус в определении важных стратегических направлений и методов, которые действенно будут работать при борьбе с терроризмом. Примечательно, что данный документ является «живым», так как Генеральной Ассамблеей предусмотрен порядок обзоров Страте- гии, проводимых раз в два года для совершенствования положений ввиду изменения ситуации на международной арене. Таким образом, документ является гибким и довольно быстро реагирует на вызовы террористических активистов.

Но до создания Контртеррористической Стратегии в рамках сотрудничества государств-членов ООН было принято в общей сложности 16 международных актов, которые регулируют вопрос борьбы с терроризмом и по своей сути являются универсальными документами.

В целом, данные международно-правовые акты разделяются по категориям преступлений. Выделим пять основных категорий преступлений, по которым идет разделение: преступления, объектом которых выступают морские суда; преступления в сфере защиты гражданской авиации; связанные с опасными материалами (в это понятие входят взрывчатые, химические, ядерные и иные опасные вещества); касающиеся сферы финансирования терроризма; преступления, которые касаются статуса потерпевших (то есть, речь идет о документах, связанных с захватом заложников и международной защитой должностных лиц).

Каждая из приведенных классификаций регламентирована конкретными конвенциями, и для более четкого понимания представляет необходимым проанализировать несколько примеров к каждой категории.

1. Пекинская конвенция, связанная с актами в отношении международной гражданской авиации (2010 год) - данный документ является объединением текстов Монреальской конвенции и Протокола к ней. Представленной Конвенцией расширяются классификации деяний и способов его совершения, которые по существу положений данного документа будут являться актами терроризма. Таким образом, террористическим актом будет признаваться: любое использование воздушного судна в целях нанесения ущерба или значительного увечья человеку, окружающей среде, а также имуществу; высвобождение и выбрасывание или же использование на борту самолета любого БХЯ (данный термином в соответствии с исследуемой Конвенцией обозначается биологическое, химическое или ядерное оружие) и другие деяния, ранее установленные конвенцией 1971 года.

Положения Пекинской конвенции несут основную цель - сконцентрировать внимание на том, что деяния направлены на причинение вреда жизни, здоровью или имуществу лиц вне пределов судна, с нарушением императивных запретов на использование БХЯ. Конвенция также устанавливает меры ответственности юридических лиц, которые финансируют терроризм - государства в соответствии с принципами национального права использует необходимые меры. 
2. Чикагская конвенция «О международной гражданской авиации» (1944) - была принята в рамках обозначенной конференции, и ее ключевым положением предусматривалось создание ИКАО.

Данной конвенцией регулируется вопрос статуса воздушного судна и когда оно находится в эксплуатации, обязанность государств предпринимать институт наказаний за преступления по захвату судна, ограничивает сферу действия, предусматривая, что положения не распространяются на судна, занятые в службе. Конвенция также содержит интересное положение о том, что применяться документ будет как для международных рейсов, так и для полета на внутренних авиалиниях, при наличии одного из условий: место взлета или посадки вне пределов территории регистрации судна или же преступление было совершено на территории другого государства. Положение 3 bis Конвенции содержит положение о том, что государства не должны применять оружие против гражданских самолетов в полете и подвергать тем самым жизнь находящихся на борту, но имеет при этом право требовать посадить судно, которое совершает полет намеренно без специального разрешения.

3. Конвенция о предотвращении и наказания за преступления против лиц, находящихся под международной защитой.

Документом регламентируются субъекты, которые в случае совершения преступления, приобретают статус потерпевших: главы государств, правительств, главы министерства иностранных дел и члены их семей, которые находятся с ним в другом государстве, а также представители, консулы, должностные лица государств, агенты межправительственных международных государств, которые имеют специальное право на защиту от насильственных преступлений против его личности и свободы. Данная Конвенция и те меры по предупреждению нападений на должностных лиц, которые устанавливаются документом и должны осуществляться странами, которые данные субъекты посещают, действительно являются необходимыми, ведь угроза от террористов для них в некоторых случаях даже более велика, чем для мирового сообщества, и это подтверждается произошедшим в 2013 году убийством миротворцев миссии ООН в Судане [6].

Также принципиально важным документов в вопросе защиты лиц является Конвенция о борьбе с захватом заложников, которая регламентирует, какие действия могут квалифицироваться как захват лиц в целях влияния на государства, а также закрепляет положение о взаимной помощи государств друг другу в таких ситуациях посредством передачи важной информации и выдачи (о необходимости подобных положений свидетельствуют частые захваты заложников, например, во Франции, особенно в январе 2015 года).

4. Конвенция о защите ядерного материала (1980);

Самым опасным видом терроризма в настоящее время является именно ядерный терроризм, поэтому вопрос о защите ядерных веществ от неправомерного использования террористами стоит очень остро.

Конвенция регулирует порядок экспорта, импорта и транзита материалов, международные уровни физической защиты таких компонентов при транспортировке внутри государства. Документом также устанавливается надлежащий режим защиты ядерных веществ, который должен обеспечить достижение целей, а именно защитить от кражи или иного захвата имущества. Дополнением к Конвенции также был добавлен ряд принципов по осуществлению защиты ядерных материалов, в частности, принцип сотрудничества государств в случае совершения противоправного деяния, ответственности стран при международной перевозке, принцип создания регулирующей основы и компетентного органа, обеспечения качества и конфиденциальности.

Важным документов в этой сфере является Международная конвенция о борьбе с актами ядерного терроризма, принятая в 2005 года. Данный документ стал уникальным, потому как был принят на основе консенсуса всех стран, без проведения голосования, и призван регулировать угрозу «на опережение», а не в качестве реакции на уже возникшую угрозу.

5. Конвенция о борьбе с деяниями, которые направлены против безопасности морских судов и протокол к ней - данный документ также устанавливает юрисдикцию государства в случае совершения преступления против морского судоходства и предусматривает условия для выдачи преступника в другие страны и иные положения.

6. Международная конвенция о борьбе с финансированием терроризма (1999 год) - является первым нормативно-правовым актом в международной практике, разграничивающим вопросы противодействия финансированию терроризма от пресечения террористических актов, то есть выделяет финансирование как отдельный вид терроризма [7].

Здесь же закрепляется определение такого преступления - это умышленное предоставление определенных средств, и лицо осознает, что средства будут использованы для совершения незаконного деяния, являющегося преступлением и на стадии подготовки к преступлению и покушению на него в соответствии с нормами международного и национального права (обязательство о криминализации данных деяний ложится 
на государства, которые являются членами Конвенции). Юрисдикция по данным преступлениям может быть расширена и будет применяться не только в случае совершения на территории государства (включая судна под флагом) или гражданином страны, но также если само деяние было совершено ради совершения другого преступления на территории государства, на борту судна, которое используется этим государством, с целью понуждения главы государства совершить какое-то действие или в отношении граждан страны, правительственных объектов за границей, включая консульства.

В дополнении к обычным видам сотрудничества стран добавляются и иные, закрепленные статьей 18, в том числе положения о выдаче лиц и взаимной помощи в различных видах (например, обмен компетентными службами, в том числе посредством Интерпола, информацией о личности, подозреваемой в совершении противозаконного деяния, а также о перемещении денежных потоков).

Все обозначенные Конвенции имеют важное значение для международного сообщества и взаимодействия государств по предупреждению террористических актов и наказанию за уже совершенные. Следует отметить, что в каждой из Конвенций прописываются особые положения, которые регламентируют формы сотрудничества государств. В связи с этим, чтобы установить, так скажем, общие нормы, которые регулировали бы общий порядок и принципы осуществления таких форм сотрудничества, в 2008 году была принята Конвенция две формы сотрудничества государств по борьбе с терроризмом [8].

При международном сотрудничестве по исследуемому вопросу, государствами должны соблюдаться сами принципы такого сотрудничества, включая принцип выдачи лиц, помощи в уголовном преследовании, привлечении к ответственности также лиц, содействующих терроризмам.

Следует отметить, что в статьях Конвенции закрепляется положение о том, что преступления, которые предусмотрены всей нормативной базой по противодействию терроризму, не будут считаться политическими. Данное положение внесено в целях эффективной взаимной помощи, чтобы в будущем избежать возможной ссылки государств на этот факт как на основание отказа от выдачи лица. Государства также при передаче определенной информации может установить определенные требования на ее применение и использование.

Акты, которые регулируют процесс международного сотрудничества государств по противодействию терроризму, могут заключаться и на региональных уровнях (например, на уровне СНГ), а также непосредственно между двумя государствами (примером может служить Соглашение между РФ и Республикой Беларусь о повышении эффективности взаимодействия в борьбе с терроризмом).

В связи с этим, не только включение самих международных и региональных актов в национальное законодательство посредством их ратификации, но также и имплементация самих норм данных актов во внутреннюю систему права просто необходима для наиболее эффективного осуществления мер по борьбе с терроризмом и единообразного регулирования данного вопроса, без противоречий в подходах к криминализации и квалификации совершенных деяний [9].

Представляется необходимым раскрыть процесс имплементации норм международных актов, связанных с борьбой с терроризмом, на примере Российской Федерации. Россия вносит вклад в становление международной нормативной базы по исследуемому вопросу, которая предусматривала бы формы сотрудничества государств и меры по эффективному предотвращению террористических актов. Например, нашей страной был внесен неоценимый вклад в Резолюцию 2199 (2015), связанную с деятельностью «Исламского государства» и предусматривающую противодействие усилению этой и иных группировок за счет финансирования от нефтедоходов и притока иностранных боевиков.

Российская Федерация последовательно имплементировала во внутреннее законодательство положения важнейших источников международного права в сфере борьбы с терроризмом и легализации преступных доходов, в частности Резолюции Совета Безопасности ООН 1999, 2001, 2003 годов. Имплементация была осуществлена путем принятия Указов Президента РФ [10] и последующего внедрения положений в различные федеральные законы.

Ряд вышеперечисленных Конвенций по видам террористических преступлений был ратифицирован еще в период существования СССР, и Россия, как продолжатель членства Союза в ООН, также на них опирается. По сути, Уголовный кодекс РФ основан на положениях УК РСФСР и Конвенциях ООН посредством имплементации их норм.

Примером может служить статья 211 УК РФ, предусматривающая ответственность за захват водного транспорта, воздушного судна или ж/д состава. Юридическим источником данной статьи является Конвенция о борьбе с незаконным захватом воздушных судов от 1970 года. Помимо этого, полная юридическая основа статьей 205, 206 и 221 УК РФ также усматривается в международных Конвенциях, о которых речь велась ранее - Конвенция о захвате заложников и Конвенция о защите ядерных ма- 
териалов. Следует также отметить Федеральный закон № 170-Ф3 «О6 использовании атомной энергии», положения которого также имплементированы из международных правовых актов.

В России также существует имплементация правоприменительная - такой обладают некоторые соглашения в рамках СНГ, Европейская конвенция о пресечении терроризма и Токийская конвенция, которые не содержат положений об обязательной имплементации, но меры, ими установленные, исполняются (например, процесс обмена информации и экстрадиция виновных лиц, если невозможна их выдача).

Таким образом, следует подчеркнуть, что на международном уровне имеется широкий правовой инструментарий в вопросе противодействия терроризму, но реализация тех мер и механизмов, что предусмотрены конвенционным сотрудничеством, зачастую зависит от множества факторов, например, политической обстановки и размытости толкования термина «терроризм» во внутренних законодательствах. Несмотря на попытки имплементировать нормы в национальные документы, не все государства готовы идти на это, считая подобные шаги посягательством на свой суверенитет, что осложняет процесс единообразного регулирования рассматриваемого вопроса. Но постоянное совершенствование международных актов и работа с государствами-членами таких соглашений, определенно предусматривает бурное развитие сотрудничества государств на международной арене и последующего выделения системы осуществления мер по защите безопасности мира от глобальной угрозы - терроризма.

\section{ЛИТЕРАТУРА}

1. Лукашук И.И. Международное право. Общая часть: учебник для студентов юридических факультетов и вузов. - с. 233.

2. Уголовный кодекс Российской Федерации от 18.12.2006 N 230-Ф3 (ред. от 27.10.2020) - (Дата обращения - 01.12.2020)

3. Конвенция Организации Объединенных Наций против транснациональной организованной преступности. https://www.un.org/ru/documents/decl_conv/ conventions/orgcrime.shtml

4. Декларация о принципах международного права, касающихся дружественных отношений и сотрудничества между государствами в соответствии с Уставом Организации Объединенных Наций.

5. Questions of Interpretation and Application of the 1971 Montreal Convention arising from the Aerial Incident an Lockerbie (Libyan Arab Jamahiriya v. United States of America), Provisional Measures, Order of 14 April 1992, I.C.J. Reports 1992, p. 114), (Режим доступа: http://www.icj-cij.org/icjwww/icocket/ilus/ilusframe. htm)

6. Конвенция о предотвращении и наказании преступлений против лиц, пользующихся международной защитой, в том числе дипломатических агентов. Режим доступа: http://www.un.org/ru/documents/decl_conv/conventions/int_protected_persons.shtml

7. Международная конвенция о борьбе с финансированием терроризма (Заключена в г. Нью-Йорке 09.12.1999) // Бюллетень международных договоров -2003 - №5 - c. 10 - 23.

8. Конвенция о взаимной правовой помощи и выдаче в целях борьбы с терроризмом 2008 г. URL: http://www.un.org/ru/documents/decl_conv/conventions/ extradition_mutlegal_assist.shtml

9. Милецкий Владимир Петрович Международный терроризм: политико-правовое измерение теории и практики противодействия // Всероссийский криминологический журнал - 2017 - №1.

10. Принятие резолюций Совбеза 00H: все Указы Президента РФ. [Электронный ресурс] - Режим доступа: http://www.consultant.ru/document/cons_doc_LAW _199515/23c447b967e7a4426596be7f9c31393fe7da9313/ - (Дата обращения - 04.12.2020) 